\title{
The future of long-term care in ten European countries: Review of policy reports and qualitative study among country experts
}

\author{
Lena Praznovszky ${ }^{1}$ (1) https://orid.org/0000-0002-8612-2652 \\ Milena Pavlova ${ }^{1}$ (D) https:/orrid.org/0000-0002-6082-8446 \\ Marzena Tambor ${ }^{2}$ (1) https://orcid.org/0000-0001-7970-6919 \\ Wim Groot ${ }^{1}$ (1) http://orcid.org/0000-0003-1035-5916 \\ Maastricht University,
}

\author{
${ }^{1}$ Department of Health Services Research, CAPHRI, Faculty of Health, Medicine and Life Sciences, Maastricht \\ University, Maastricht, the Netherlands \\ ${ }^{2}$ Department of Health Economics and Social Security, Institute of Public Health, Faculty of Health Sciences, Jagiel- \\ lonian University Collegium Medicum, Cracow, Poland
}

Address for correspondence: Milena Pavlova, Department of Health Services Research, Faculty of Health, Medicine and Life Sciences, Maastricht University, PO Box 616, 6200 MD Maastricht, the Netherlands, +31 433881705 , m.pavlova@maastrichtuniversity.nl

\section{Abstract}

The provision of good quality long-term care to citizens represents a challenge for many European countries due to tight public budgets and ongoing societal transitions. To gain insights on the future of long-term care in Europe, an explorative study was conducted consisting of a review of policy reports and qualitative study among country experts from Albania, Bulgaria, France, Germany, Lithuania, the Netherlands, Poland, Portugal, Ukraine, and the United Kingdom. For the purpose of the analysis, a conceptual framework was developed. Based on this framework, the method of qualitative directed content analysis was applied to extract and analyze information from the reports and study transcripts. The results suggest four key directions for long-term care development: (a) integration, coordination and cooperation across structures and actors for better service quality; (b) increased scope and scale of formal service provision; (c) improved workforce planning and capacity building; (d) use of e-health and information technologies. The exact direction is however dependent on the country-specific guiding principles, governance capacity and funding constraints. To adequately respond to current challenges, policy-makers need to acknowledge the interconnectedness of long-term care issues and approach them from a more holistic perspective.

Key words: country experts, Europe, funding, governance, Iong-term care, management, review

Stowa kluczowe: eksperci krajowi, Europa, finansowanie, rządzenie, opieka długoterminowa, zarzadzanie, przegląd

\section{Acknowledgements}

We would like to thank the country experts who participated in this study, for offering their expertise and dedicating their time thereby contributing to this study.

Milena Pavlova is the recipient of an AXA Award of the AXA Research Fund, Project "EuroLTCS Project - Innovative Mechanisms for Sustainable Long-Term Care Systems in Europe". The content of this publication represents the views of the authors and it is their sole responsibility; it can in no way be taken to reflect the views of the AXA Research Fund.

Przygotowanie do wydania elektronicznego finansowane w ramach umowy 637/P-DUN/2019 ze środków Ministerstwa Nauki i Szkolnictwa Wyższego przeznaczonych na działalność upowszechniającą naukę. 


\section{Introduction}

The provision of good quality long-term care (LTC) to citizens, represents a challenge for many European countries. Declining birth rates and ever-improving health care services result in increasing proportions of aged individuals in need for complex care. Due to the diverse daily needs of older individuals, however, the capacity of the established LTC systems to provide adequate responses, has been questioned [1]. Shortages in the care workforce, with an increasing disbalance in the recipient/provider ratio, endanger the quality of care. Although informal care provided by family members, may conceal the lack of formal services, it retains workforce from the paid labor markets and thereby, from the necessary financial contributions to taxation and insurance schemes [2 p. 66]. At the same time, austerity measures introduced in the aftermath of the last financial crisis, limit the capacity of households to spend on private care services and supplementary welfare schemes [3, 4].

European countries are also struggling to finance LTC from taxation and cross-generational solidarity schemes. To make the best use of available resources and improve care for recipients, experts in the field have pointed towards the need for increased integration in LTC, which includes improved co-ordination as well as adjustment in administration and delivery of care on all levels [5]. Scarce financial and human resources, as well as organizational structures in need of improvement, have compelled many European countries to reform the established LTC systems or at least to consider changes. Such reforms have been focusing on the key aspects of LTC, for example on increased financing for care in France and Poland; strengthening informal care workers in the United Kingdom; or adjustment of eligibility regulations in Germany [6].

However, policy makers focused on the development of future LTC policies, are confronted with a multitude of challenges. While prioritization is important to respond to present crises, sustainable policies are needed throughout all LTC segments. Although the European Union (EU) might indicate directions for the reforms, ultimately, it lies within the responsibility of each European country, to react to the challenges of LTC and to shape adequate and feasible policy on the national level.

Much research has been conducted to generate better understanding of European LTC systemic structures $[1,7]$. Still, more ought to be known on the future direction of LTC in Europe, especially regarding national views on this issue and approaches how to react to main challenges. This is not only needed to better understand the general trajectory of European LTC systems but also to identify areas for possible future cooperation and mutual learning between EU member states and beyond. This paper contributes to the body of knowledge on LTC in Europe by providing information for consultants and politicians at the stage of problem identification and agenda setting [8]. More specifically, the aim of this paper is to provide insights on the views, opinions and expectations on the current state and future of LTC sectors in European countries. Hereby, this study follows a qualitative approach based on the analysis of policy reports, as well as data collected among country experts through online questionnaire and follow-up online interviews.

\section{Methodology}

In this section, the conceptual framework used in this study is presented. This is followed by the description of materials used and research methods applied to meet the aim of the study.

\section{IIC system model}

Research in the field of LTC can draw upon a variety of existing frameworks and conceptualizations of LTC systems as a tool for analysis. Still, it may be expedient to start from a health systems perspective, then extending it to do justice to the complexity of LTC systems. Thus, for the purpose of gaining insights into the future of European LTC sectors, a conceptual framework is developed from a fusion of the WHO Health System Performance Framework and the INTERLINKS Framework of LTC. This is thought to be feasible, as the building blocks in the WHO Health System Performance framework, provide a good basis for system analysis but are restricted to health systems. This is accounted for by adding key themes and issues form the INTERLINKS Framework developed by the European Centre for Social Welfare Policy and Research in cooperation with thirteen European countries $[1,9]$. The conceptual framework is presented in Figure 1.

As shown Figure 1, the seven dimensions formed through the fusion of both frameworks, provide a broad typology of main sectors within the LTC systems. It is important to point that in practice dimensions may overlap in various constellations. Due to the difficulty of depicting this interconnectedness, the discrete dimensions are presented in a circle formation.

In our application of the conceptual framework in this study, we considered the following questions per dimension:

- LTC guiding principles: What are the roles and responsibilities of families and government in LTC? How are ageing and LTC-needs framed (e.g. from a health care perspective, or with a focus on social inclusion and autonomy)?

- LTC governance: Are LTC regulation, administration and provision centralized or decentralized? Is there a sound legal framework for LTC on the national and regional level? What is the role of the market mechanisms in LTC (e.g. consumer choice, competition)?

- LTC financing: Is there a dedicated source of public funds for LTC (LTC insurance)? Are public resources dominant or is LTC rather privately financed (through out-of-pocket payments or private insurance)? Are the mechanisms used to pay LTC providers, input-based (like global budget), output-based (like fee-for-service) or outcome-based (like pay-for-performance)?

- LTC service delivery: Who receives services in terms of eligibility indicators? In which settings are LTC 


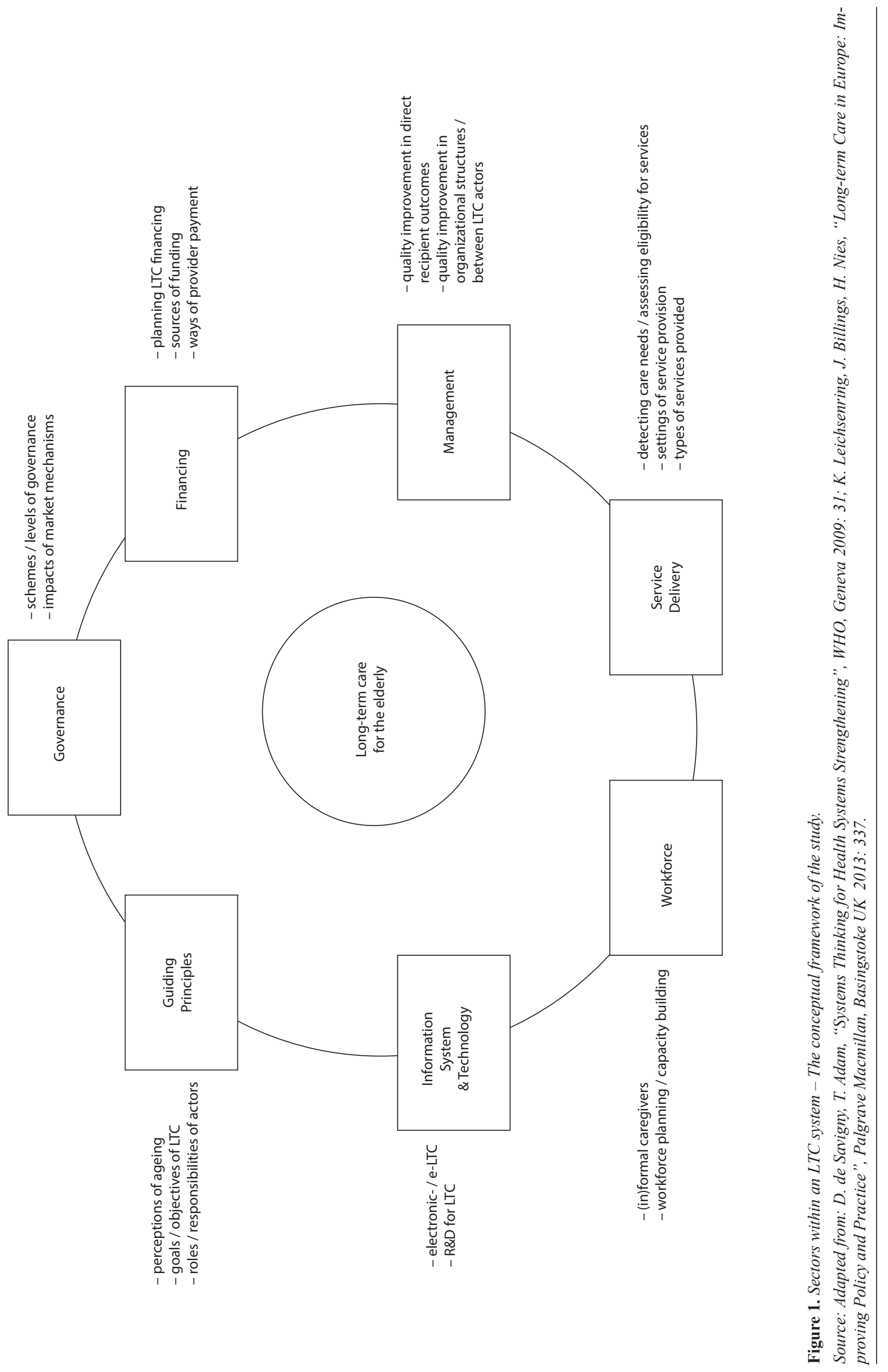


services provided (e.g. in institutional environments, at home or in multigenerational housing concepts)? What kind of LTC services are provided (e.g. services for recipients or informal carers, as cash or in-kind, nursing or household aid)?

- LTC management: How can quality of care be improved, including formal and informal care (e.g. recipient's experience of care delivery or the communication between LTC actors)? How can the organization and coordination of LTC be improved?

- LTC workforce: Is care rather provided through formal or informal care givers? And is there an agenda for increased capacity building in both types? What professions are involved in formal care provision (e.g. nurses, social care workers, etc.)?

- LTC information systems \& technology: What is the state of embedding ICT (information and communications technology) in LTC (e.g. the use of ICT in the provision of home care or exchange of information)? What is the capacity of implementing or funding such technologies in LTC?

\section{Materials and methods}

To meet the aim of this study, an explorative cross-country qualitative research method was applied. The study included two phases: (a) analysis of policy reports and (b) a qualitative study among country experts on their views, opinions and expectations regarding the future of LTC sectors within their countries. The following countries were included: Albania (AL), Bulgaria (BG), France (FR), Germany (DE), Lithuania (LT), The Netherlands (NL), Poland (PL), Portugal (PT), Ukraine (UA) and The United Kingdom (UK). The aim was to include a wide range of countries representing different parts of Europe and different welfare state regimes (conservative, liberal, social-democratic, southern and eastern), including also countries outside the EU (Albania, Ukraine).

\section{Analysis of policy reports}

To provide a basic overview on the state of LTC in each country, we carried out a narrative (non-systematic) literature review. The objective was to identity key recent policy reports on health systems and LTC systems for each country, in particular reports published by WHO, OECD and the European Commission (Directorates ECFIN and EMPL). Given this objective, the following documents were selected for analysis:

- The WHO Health Systems in Transition series, which is developed by the European Observatory on Health Systems and Policies, and offers an in-depth account of national health care and partly of social care systemic structures.

- The Joint Report on Health Care and Long-Term Care Systems \& Fiscal Sustainability, developed by Directorate ECFIN and the Ageing Working Group of the Economic Policy Committee, which has a focus on finance, and provides extensive information on country's health care and LTC systemic structures.
- The Thematic Report on Challenges in LTC series, of the European Social Policy Network (ESPN) which provides an updated and specific information on European national LTC.

- The Health at a Glance report of EU and OECD provides a comparison of expenditure indicators.

These sources were chosen, as they provide comparable and reliable data on the EU member states. As it proved difficult to obtain data for non-EU countries through the above sources, additional sources were added for Albania [10-12] and Ukraine [13-15]. Besides, two background papers were included $[13,16]$.

The sources were analyzed to extract information on the characteristics of the national LTC systems: current state and future directions. As national institutional structures in the field of LTC are complex, and the selected policy reports are comprehensive, a complete presentation of the national LTC systems is outside the scope of this paper. The results are focused on providing an overview of national LTC in the countries included in this study, based on the seven dimensions of the LTC model presented in Figure 1. To limit the amount of information presented here, one subcategory of each dimension was chosen at the researcher's discretion.

\section{Qualitative study among country experts}

For the purpose of this study, experts (informants) from 16 European countries were invited to participate. The experts were chosen based on a non-probabilistic convenience sampling technique. Specifically, experts from the professional networks of the researchers, were contacted. All experts were university-level researchers with a holistic view on the LTC sector in their country. Participants from the academic field, were considered suitable to express their views, opinions and expectations on the future of national LTC, as they obtain a professional, critical view on tendencies and developments. The advantages of conducting expert interviews have been shown in previous studies $[17,18]$. Experts from ten countries (Albania, Bulgaria, France, Germany, Lithuania, the Netherlands, Poland, Portugal, Ukraine, and the United Kingdom), accepted to participate. Each country was represented by one expert. Table I presents a summary of their characteristics. We could not identify a suitable expert from Denmark, Finland, Greece, Hungary, Italy and Ireland, despite the contacts in our professional networks.

A set of basic open-ended questions was developed in English language, covering the seven dimensions of the LTC system, as demonstrated by the conceptual framework in Figure 1. The questions were directed towards gathering data on views, opinions and expectations regarding the future of LTC in the participants' countries, and were formulated in a way that they were relevant and comprehensible for the participant. The set of basic questions was used to develop a questionnaire document, which was sent to participants via email. At the beginning of the questionnaire, a question on informed consent was included, and participants could provide information 


\begin{tabular}{|c|c|}
\hline Characteristic & Number of participants \\
\hline $\begin{array}{l}\text { Gender } \\
\text { Male } \\
\text { Female }\end{array}$ & $\begin{array}{l}3 \\
7 \\
\end{array}$ \\
\hline $\begin{array}{l}\text { Age } \\
\text { Up to } 30 \text { years old } \\
31-4 \\
41-50 \\
51-60 \\
61-70\end{array}$ & $\begin{array}{l}1 \\
1 \\
3 \\
3 \\
2\end{array}$ \\
\hline $\begin{array}{l}\text { Non-university level vocational training: professional education completed } \\
\text { Yes } \\
\text { No }\end{array}$ & $\begin{array}{l}2 \\
8\end{array}$ \\
\hline $\begin{array}{l}\text { Highest grade of education completed } \\
\text { Post-graduate work doctoral level } \\
\text { Not reported }\end{array}$ & $\begin{array}{l}1 \\
9\end{array}$ \\
\hline $\begin{array}{l}\text { Field of academic education completed } \\
\text { Health Sciences } \\
\text { Medicine } \\
\text { Social Sciences } \\
\text { Economics } \\
\text { Engineering/Technology }\end{array}$ & $\begin{array}{l}4 / 10 \\
2 / 10 \\
3 / 10 \\
7 / 10 \\
1 / 10\end{array}$ \\
\hline $\begin{array}{l}\text { Connection of the topic LTC to own work } \\
\text { Research } \\
\text { Teaching } \\
\text { Practice/Occupation }\end{array}$ & $\begin{array}{l}10 / 10 \\
6 / 10 \\
2 / 10\end{array}$ \\
\hline $\begin{array}{l}\text { Time LTC has been the main topic/central issue in own professional work: } \\
\text { Up to } 5 \text { years } \\
6-10 \text { years } \\
11-20 \text { years }\end{array}$ & $\begin{array}{l}5 \\
2 \\
3\end{array}$ \\
\hline $\begin{array}{l}\text { Activities in the field of LTC: } \\
\text { Publication in peer-reviewed journals } \\
\text { Teaching university level } \\
\text { Teaching/consultation on the government (national/local) level } \\
\text { Participation in LTC-related conferences } \\
\text { Participation in non-governmental projects in LTC } \\
\text { Current work in close dialogue with LTC providers } \\
\text { Current work in close dialogue with LTC recipients } \\
\text { Personal experience/involvement with LTC (e.g. family members) }\end{array}$ & $\begin{array}{l}8 / 10 \\
5 / 10 \\
4 / 10 \\
7 / 10 \\
6 / 10 \\
1 / 10 \\
1 / 10 \\
3 / 10\end{array}$ \\
\hline
\end{tabular}

Table I. Participants' characteristics $(N=10)$.

Source: Own study.

on their personal profile. At the end of the questionnaire, information about the subsequent steps, was given.

The data collection process consisted of two steps: filling in the online questionnaire and follow up online interviews (alternatively email correspondence) to discuss the answers filled in the questionnaires. A formal email including the questionnaire document, was sent to the email address indicated by the participants. The email contained background information on the research project, while instructions for filling in and returning the questionnaire was included within the questionnaire. Participants were given 14 days to fill in their answers. If necessary, after the $14^{\text {th }}$ day, a reminder was sent to the participants followed by an optional 14 days extension of the deadline. The received questionnaires were reviewed and used to prepare additional clarifying questions. Participant were then contacted for a short interview to discuss the answers to the basic questions and to clarify any additional questions, if needed. Alternatively, additional questions were clarified via email correspondence. The follow-up interviews were carried out via Skype or WhatsApp call, depending on the participant's preference. During the follow-up interviews, notes were taken.

The filled-in questionnaires and transcripts (notes) of the interviews were analyzed through the method of directed qualitative content analysis. This is a deductive approach based on pre-defined themes and data extraction is based on a template covering these themes [19, 20]. In this study, the themes were the key dimension of LTC systems presented in Figure 1. For the purpose of the analysis, a template per country was developed covering the key LTC dimensions. The data extracted in the country templates, were synthesized and were presented in the form of narrative description per dimension. The country templates can be provided by the authors on request. 


\section{Ethical considerations}

Prior to the data collection, ethical approval was received from one of the ethics committees at the Maastricht University. Participants filled in an informed consent form, which was attached to the questionnaire. All data collected in this study were treated with great caution to avoid any actions, which could have disclosed the participants. Specifically, to safeguard confidentiality and privacy of participants, results from the qualitative analysis were presented for all countries or a group of countries indicating the frequency of arguments without statements about the individual countries (which could directly disclose our raw data since we had only one expert per country). For all ways of communication with the participants and processing of related data, the Maastricht University email account and virtual private network were used, as they operate under higher security standards.

\section{Results}

The policy reports listed in the Methodology section and data collected among the country experts, are used to analyze the current state of LTC systems in the selected countries as well as the vision for their future, based on the seven dimensions of the LTC model presented in Figure 1. The results of the two parts of the study are presented together per dimension, starting with current state followed by the experts' opinions on future developments.

\section{Guiding principles - goals/objectives of LTC}

As suggested by the policy reports reviewed, across countries, the goals and objectives of the national LTC systems are frequently defined in policy documents. Broadly, they can be categorized into service-related goals and objectives (outputs), as for example health prevention and rehabilitation, comprehensiveness of services, availability and accessibility; or user-related goals and objectives (outcomes), such as avoidance or delay of dependency, social participation, autonomy, dignity and the recognition of user needs. Still, national ambitions to achieve goals and objectives, such as increased accessibility and affordability, are not necessarily adequately represented in subsequent policies or legislation, which are especially lacking in Albania and Ukraine.

The predominant aim of LTC policy, visible for all ten countries, is to prevent or delay dependency of individuals on state or family support. In the LTC domain of health care, this is visible in actions towards health protection and promotion (BG, DE, FR, LT, NL, PL), avoiding recurring hospital admission (BG, DE, FR, NL, $\mathrm{PL})$ and strengthening rehabilitative measures (BG, DE, FR, LT, NL, PL, PT). While initiatives in the field of geriatrics might be existent in all ten countries, they are only explicitly visible in documents in France, Lithuania and Albania.

A second aim focusses on user-related rights and interests. Most visible are initiatives for social inclusion of elderly people, as prevention of loneliness or isolation (BG, DE, FR, LT, NL, PL, PT). Besides, the possibility for elderly individuals to lead autonomous lives (BG, DE, FR, LT, NL, PT, UK), in dignity (BG, FR, PL, PT, $\mathrm{NL}$ ) and to co-determine the organization of care received (BG, DE, LT, PL, PT, UK) are also considered in national LTC documents.

Lastly, the aim of LTC services to provide good quality of life (BG, LT, PT) and to be generally ample (BG, DE, FR, PT) is also apparent in the countries.

On the current state of guiding principles in LTC, country experts mainly mention the roles and responsibilities of various actors, especially of families and communities $(N=4)$ and of the central and regional authorities $(N=4)$. Further, a variety of views on LTC in public discourse $(N=3)$, for example the role of institutionalized care, are mentioned. Some country experts describe sustainability as a service-related value $(N=3)$, and independence as recipient-related value $(N=2)$, as well as trends towards more recognition of needs $(N=2)$ in the perception of ageing.

The state of service-related values is assessed as a main challenge of the LTC guiding principles $(N=7)$, followed by differing views on LTC $(N=5)$, for example on the use of new technologies in care provision. Furthermore, a concern is expressed to an equal extent on the state of user-related values $(N=4)$, such as access to services $(N=4)$ and independence $(N=2)$. Country experts point as well towards the issue of the role of family in care provision $(N=4)$, in the presence of changes in family structures, such as increasing female labor participation. To a lesser degree, the framing of elderly persons' needs $(N=2)$ is mentioned as possibly problematic.

In future, the need for more access to care $(N=4)$, for more flexible and customizable services $(N=4)$ and more demand-based LTC provision $(N=2)$ is expected, as well as more focused LTC policy $(N=3)$, for example clear definitions of LTC. While country experts assume more central and regional authority obligation to enable formal LTC provision $(N=3)$, the role of family care is expected to remain $(N=2)$. Future recognition of holistic care needs $(N=1)$ is described as desirable.

\section{Governance - schemes/levels of LIC yovernance}

The policy reports indicated that across the ten countries, the division of regulatory action and decision-making is shared between the domain of health care (such as health ministry/national insurance funds) and the domain of social welfare (such as ministries of labor or social security/ social insurance) as well as between central and regional authorities.

In all ten countries, LTC legislation is adopted by the central government within the frame of either health or social policy. Mostly, legislation on LTC is apparent in social policy (NL, FR, UK) and policies on ageing (LT, FR). Lack of clear legal definition of LTC and inherent services is an issue in some countries, as for example in Bulgaria. Supervision of public insurances and health care or LTC institutions (DE, LT, NL) is also exerted 
from the central government level. The same holds for decisions on health and social care spending (BG, NL, PT, UK).

National health ministries support the development of health and LTC policies (BG, LT, NL, PL, PT). Likewise, ministries of labor or social security are involved in developing social policy (BG, LT, PL), and may contribute to the creation of LTC-related institutions, as in the case of Portugal. Few countries show distinct LTC institutions, or LTC insurance (NL, DE, PT). In Germany, LTC funds carry responsibility for access to home care.

The most visible responsibility of regional authorities or governments is to guarantee access to institutional care and social security services by allocating the budgets accordingly (BG, DE, FR, LT, NL, PL, UK). Besides, there may be some discretion on how to implement national policies on the local level (FR, PL, UK). On this level, decisions are made on the need for and eligibility of admission to care (LT, NL, PL, UA, UK), as well as on quality assessment of care provided (DE, LT, PL). Social care institutions may verify the need for LTC locally and decide on the care organization (BG, FR, LT, NL, PL, $\mathrm{UK})$ as well as on the administration of monetary social benefits (DE, FR, PL, NL).

On the governance in LTC, country experts comment mostly on existing structures $(N=6)$ and trends towards decentralization $(N=5)$, while to a lesser degree on ongoing reforms $(N=4)$. The role of the market mechanisms is mentioned with regard to financial incentives $(N=3)$, for example to invest in e-health, and regarding government interventions $(N=2)$. LTC legislation and the following implementation $(N=4)$ are assessed as a challenge, exactly like the impeding factor of existing hierarchical structures $(N=4)$. The organization of LTC on the regional/local level is also assessed to be problematic $(N=2)$. The lack of government financial investment $(N=2)$, for example, in e-health, and competition $(N=3)$ is named as market-related challenges.

In future, more LTC-specific legislation $(N=5)$ is expected, and to a lesser degree a shift from institutionalized care towards home care $(N=3)$. While trends towards decentralization are expected $(N=4)$, regional authorities may continue to play a role in LTC depending on the central authority support $(N=3)$, for example in financing services. An increase in private care services is expected $(N=3)$ as well as an increase in competition $(N=2)$, for example between providers to attract care workers.

\section{Financing - sources of LTC funding}

The policy reports distinguish between funding of health care and funding of social care for LTC recipients. Throughout the ten countries, health care for elderly persons at home or in institutional settings, is covered under the corresponding national health schemes (insurance or tax-based), but out-of-pocket payments may also apply depending on national health system regulations.

At the same time, social care spending is frequently financed from the central taxation (BG, FR, LT, PL, UK).
In Germany and the Netherlands, there is LTC insurance funded via employer contributions and employee salary deductions. Budgets are transferred to the regional level (BG, PL, NL, UA). Regional authorities and governments commonly carry the responsibility of financing social care provision from budgets received from the central government or taxes levied locally (BG, FR, NL, PL, UA, UK). Hereby, national austerity cuts influence the access to care negatively (NL, UK). Care recipient's private financial resources are therefore an important source of funding social care in most countries (BG, DE, FR, LT, NL, PL, PT, UK). The same applies for means-tested payments for institutional care (BG, DE FR, LT, NL, PL, UK). Pensions or other welfare benefits are the universal mean of financing own care, if users do not dispose of substantial own funds.

The role of the EU structural funds in developing regional LTC services, is especially reported for Poland, Lithuania and Portugal. The role of ministries in funding LTC is not clearly visible from the policy reports analyzed, while in Portugal the Ministry of Health contributes financially to national LTC institutions, and ministries for social affairs contribute to LTC in both, Portugal and Bulgaria. The role of private LTC insurance varies greatly across countries. It is common in France and Germany, but marginal in Bulgaria and Ukraine.

In a few countries, family members have a legal obligation to support elderly people in- kind or in financing their care (DE, FR, UA), while this is not the case in some other countries (NL, PL, PT, UK). Still, strong traditional perceptions on family members as support at old age, are apparent in all ten countries and are vital where there is insufficient public LTC service provision (AL, UA).

Users who are eligible for direct cash payments to finance care, may use those payments to remunerate informal care givers (DE, LT, PL, PT, UA). Yet, in some countries, spending is subject to close supervision (FR, NL, UK). Direct cash payments to users are not available in the Netherlands. Sometimes caregiver qualify for cash benefits, yet national conditions differ (DE, NL, PL, PT, UA, UK). It may, for instance under certain conditions be possible to take up by caregivers paid employment simultaneously (DE).

Regarding the current state of LTC financing, country experts mention the policy discussion related to sources of funding $(N=5)$ and changes in funding $(N=5)$, and to a much lesser degree, discussion on the existing ways of formal provider payment $(N=1)$. As the main challenge in funding LTC, country experts state the difficulty of funding current care needs $(N=8)$, followed by the difficulty of budgeting for future care needs $(N=6)$. Additionally, the issue of developing strategies for informal care work remuneration $(N=1)$ is also mentioned.

For the future, country experts expect trends towards outcome-based payment mechanisms in provider payment $(N=4)$ and overall trends towards more public funding $(N=2)$, changes in public funding mechanisms $(N=2)$ and continued co-payments by LTC recipients $(N=2)$. 


\section{Management - quality improvement in LTC organizational structures}

According to the policy reports, all ten countries generally recognize the need for more integration between LTC decision-making bodies, providers and care recipients. Improved cooperation is thereby seen as an essential step in achieving better care outcomes for the recipient by using national resources efficiently (FR, NL).

Policies to reduce barriers for LTC development between central and regional authorities have been implemented by most of the countries, with a general trend towards decentralization and conferral of responsibilities to regional levels (AL, BG, DE, FR, LT, NL, PL, $\mathrm{PT}, \mathrm{UK}$ ). The need to reduce regional variations in access to care has been expressed, especially regarding elderly individuals living in rural areas with low infrastructures (AL, FR, LT, PL, UA). Additionally, policies have focused on the transition from institutionalization towards more community-based care provision (BG, FR, LT, PL, PT), as for example by encouraging home modification to facilitate home care (FR, DE).

Action for closer cooperation between health care and social care institutions have been implemented for example through institution building on regional level (FR, PT), or by legislation on revised responsibilities of both sectors (BG, FR, NL, PT, UK). Another trend is the strengthening of temporary care solutions for elderly people after a hospital discharge (BG, FR, PT). Besides, an exchange of experience between different professionals in care provision and the creation of multidisciplinary work teams have been pushed forward (BG, PT, UK).

Some countries are found to have supervisory bodies for accreditation and performance assessment of LTC institutions and care providers (BG, DE, LT, NL, PL, UK). They partially offer services of complaints management (LT, NL, PL, UK). Besides, initiatives for connecting informal carers, are resulting in a stronger visibility and consideration of their interests (FR, PT).

Regarding the state of LTC management, the country experts indicate likewise trends towards more quality improvement in the outcomes for care recipients $(N=3)$ and within organizational LTC structures $(N=3)$. Subsequently, trends in linking social and health care $(N=2)$ are described. Still, the persistent lack of overall integration of LTC organizational structures and between actors $(N=7)$ is formulated as the main challenge in LTC management. Also, the lack of concrete strategies $(N=3)$ and the lack of human resources $(N=3)$ are assessed as key challenges. Country experts also mentioned the lack of strategies for quality assessment of care outcomes $(N=3)$, especially in informal care.

Regarding the future of LTC, most country experts expect trends towards more integration in LTC organizational structures $(N=8)$, especially between social care and health care $(N=5)$. Also, the improvement of the direct outcomes for the recipients, is estimated to increase $(N=4)$. Trends towards more concrete strategies $(N=2)$, more human resources such as specific skills $(N=2)$, and more cooperation in organizational structures $(N=1)$ are also named in the experts' opinion.

\section{Service delivery - settings of LIC service provision}

In the ten countries, LTC services are received either in institutional environments or at the user's home, as indicated by the reviewed reports. Besides, there are mixed forms such as limited stay in day-, night- or transitional care facilities (BG, FR, DE, LT, NL, PL, PT, UA, UK). Access to formal care is generally dependent on the development of national LTC structures and resources. For example, the LTC spending as percentage of GDP in the Netherlands is high because formal LTC structures are widely established. In comparison Bulgaria, for which percentage of GDP spending on LTC is lowest among the EU member states, related LTC structures are found to be scarce.

Across the ten countries, home and community care is generally preferred over institutionalized care by citizens and national governments (AL, BG, DE, FR, LT, NL, PL, UA, UK). Where there is a lack of access to formal care services at home or financing issues related to these services, formal institutional care is considered as option, nevertheless informal care at home is the service mostly preferred by users (BG, LT, PL, PT).

LTC services are related to either the health care or social care domain. A recurring pattern across countries is that care recipients with health care needs have these needs met under the former domain (health insurance/ national health service), while where health care needs are not the main reason for care, or users lack own financial means to purchase care privately, they are met by the latter domain (social insurance/social security schemes). Another differentiation can be made for service supply by provider, such as public organizations, private for-profit or private non-for-profit (such as NGOs and religious groups). Where health services are easier accessible or more affordable than social services, or when no alternative LTC solutions are at hand, people in need of care may turn to secondary health care providers (e.g. using inpatient hospital care instead of residential care resulting in "social care" beds in hospitals). While this is the case across all ten countries for acute and chronic care hospital wards, it is especially mentioned for Poland, Ukraine and the United Kingdom. Such bed occupancy is partly based on repetitive readmission on grounds of health care needs. As a result, hospital beds are unnecessarily occupied and cannot be accessed by other patients (PL, UA, UK).

In some countries, residential care under the domain of health care is additionally provided in nursing homes or hospices (BG, DE, FR, LT, NL, PL, PT, UK). Provision of residential care under the domain of social care is apparent in social assistance or retirement homes. Such homes are predominantly under public stewardship (AL, BG, DE, FR, LT, NL, PL, PT, UA), or else they are under stewardship of private not-for-profit (AL, BG, DE, LT, NL, PL, PT, UK) or by private for-profit organizations (AL, BG, DE, LT, PL, PT, UA, UK), with the latter commonly charging high prices to users.

Home care under the domain of health care is commonly offered via mobile health care staff, such as nurses 
or assistants, who may work as self-employed or are employed at primary or secondary health care facilities (AL, BG, DE, FR, LT, NL, PL, PT, UK). Under the domain of social care, non-medical home support/assistance is provided either by professional teams of public institutions (AL, BG, FR, LT, NL, PL, PT, UA), by private not-forprofit (AL, BG, DE, FR LT, PL, PT, UK), or by private for-profit providers (AL, DE, LT, NL, PL, PT, UA, UK). The important role of traditional religious institutions in enabling community-based and home-based care support are visible throughout the ten countries.

Besides, there are mixed forms of available care settings, including day/night care, which often bridges the time of informal carers absence (BG, DE, FR, LT, PL, PT, UA, UK), sheltered housing or assisted living solutions (BG, FR, LT, NL, PT, UA), as well as transitional care for care recipients with health care needs (BG, DE, FR, NL, PL, PT, UK). These mixed types are frequently publicly provided under the domain of social care $(\mathrm{BG}$, NL, PL, UK).

On the state of national service delivery in LTC, country experts mostly mention trends towards more service provision, both at home and in institutional settings $(N=6)$. Changes in the focus of eligibility criteria for receiving care are stated by three country experts, while the existence of eligibility criteria $(N=1)$ and usage of services by type of benefit $(N=1)$ are less visible. The limited range of health care and social care services is named by the country experts as a major challenge $(N=4)$, followed by concerns on patterns of service usage $(N=2)$, as cash benefits intended for care spending may compensate for low personal disposable income instead. The challenge of availability $(\mathrm{N}=2)$ and accessibility $(\mathrm{N}=1)$ of services is also mentioned, yet les often.

Regarding the future of national LTC services, general trends towards more service provision $(N=6)$ are mostly stated. Subsequently, country experts address trends in provision especially towards home care and community care $(N=3)$ and towards private providers $(N=3)$. Country experts point towards the issue of failing to detect complex care needs in future $(N=2)$, and the need for more holistic eligibility indicators $(N=1)$. Lastly, a future trend of more provision especially by public providers $(N=2)$ is expected.

\section{Workforce - LIC workforce planning/capacity building}

Initiatives to match future care needs with adequate workforce capacities may follow two separate directions, as indicated in the policy reports reviewed. Firstly, they aim at mobilizing the human resources of informal caregivers, which appears to be the predominating strategy, as informal caregivers are vital to secure home care for the elderly persons. Secondly, they aim at strengthening formal care professionals.

The former group of initiatives includes policies offering caregivers more flexibility in delivering care, as respite care under country-specific conditions (DE, FR, LT, NL, PL, UK) and leave from paid work which is accompanied with financial benefits in some countries (BG,
DE, FR, NL, PL, UK). Besides, welfare benefits may, under conditions, be available to informal carers (DE, LT, PL, UA, UK). Actions to equip informal carers with professional knowledge and coping skills have been taken by most of the countries, even though partially on the local level and by private (non-for- profit) initiatives only (BG, DE, FR, LT, NL, PL, PT, UK).

The latter includes policies to establish new occupational profiles (BG, PL), to make existing care professions more appealing on job markets (DE, FR, NL, PT) and to confront national issues of care workforce migration, a pressing issue for Bulgaria, Lithuania, Poland and Ukraine. In addition, various countries have taken general actions towards increasing the quantity of care workers (BG, DE, FR, NL, PT). As indicated by the reports, only Portugal has genuinely approached the recruitment of informal carers as formal care professionals.

For the current state of LTC workforce, country experts describe the state of political discussion on care workforce capacity-building $(N=3)$ and on benefits for informal caregivers $(N=2)$. Besides, informal caregivers are mentioned as important resource $(N=2)$. A major challenge in planning care workforce, is emigration of care workers $(N=5)$. Besides the lack of care training and skill development $(N=2)$, some country experts mention a general decline in young workforce $(N=2)$ and the issue of care work being unattractive on job markets $(N=2)$.

In future, informal care workers are expected to remain an important resource $(N=3)$, and to be supported and encouraged $(N=2)$. Trends towards higher remuneration $(N=4)$ and increased training and education $(N=3)$ are anticipated regarding the formal care workforce.

\section{Information systems \& technology - e-LIC}

The development and implementation of electronic health data policies varies across the countries analyzed. The policy reports indicate that electronic user records and data exchange between LTC actors are thereby still confined to the domain of health care. Nevertheless, progress in e-health may simultaneously strengthen "e-LTC", improving electronic data exchange in the organization of care for the elderly persons. The social care dimension of LTC is not incorporated in national e-health programs and while recipient-related data sharing between social care administrative bodies may be in place, no related information could be found in the analyzed policy reports.

Common technologies to support health care for elderly persons are the verification of entitlement for health services at point of use (BG, DE, PL, PT) and the electronic documentation of patient data by providers (BG, DE, FR, LT, NL, PL, UK). Actions towards increased use of new technologies and e-health are visible in various countries, as for example encouraging of tele-care in the provision of care at home (FR, PL); the establishment of electronic data platforms either allowing for data exchange between care actors and improved user-access to medical records and information (BG, DE, FR, LT, NL, PL, PT, UK), or as medium for accreditation and monitoring procedures (BG, LT, NL, PL). 
Comparable information for Albania and Ukraine could not be found in the policy reports analyzed, while electronic documentation of medical data is established in both countries.

Regarding the current state of LTC information systems and technology, country experts describe mostly the state of e-health/e-LTC development $(N=8)$ and to a lesser degree the role of private organizations $(N=2)$ and public funding $(N=1)$ in R\&D for LTC. As main challenge for e-LTC, existing organizational structures are mentioned as inhibiting factor $(N=4)$, but also the lack of resources $(N=2)$. Both are assumed to continue in future $(N=1)$ respectively. The effectiveness $(N=1)$ of newly developed products is as well seen as critical issue. In future, trends towards more e-LTC $(N=7)$ and more innovation $(N=1)$ are expected.

\section{Discussion}

Based on the views, opinions and expectations regarding the future of the LTC sectors in Europe, results suggest four main concerns related to LTC management, service delivery, workforce as well as information systems and technology respectively. The other foundation elements of the LTC systems (see Figure 1), namely guiding principles, governance and financing, are also connected although inexplicitly. The four main concerns are subsequently discussed.

\section{Integration, Coordination and cooperation across LIC structures and actors}

The first main concern relates to the integration, coordination and cooperation across LTC organizational structures and between LTC actors, which fall under the dimension of LTC management.

A lack of integration across organizational structures is still perceived as an important challenge in the countries included in this study. Country experts partially attribute it to persisting hierarchical structures within and between institutions and between individual actors. It might be also explained, by the historical development of institutions and of the relationships between different professions. As previously pointed out by Pfau-Effinger [21], path dependency is an important mechanism, which can inhibit societal transitions. Therefore, established (hierarchical) structures and beliefs about competencies, may only slowly give room for new approaches [22]. Concerns of negatively impacting quality of care when following established structures, are also expressed in this study, urging towards structural changes in future. This is in line with the literature on the importance of care integration to improve channels of communication between providers and generate better care outcomes, also through user empowerment [23-25].

Another ongoing concern related to quality of care is the lack of clear LTC legislation. While country experts already describe ongoing change in governance, such as shifts of responsibilities from the central to the regional or municipal level, further changes are requested for LTC legislation, which is thought to be insufficient or failing to integrate the domains of health and social care. Action in the dimension of governance is a prerequisite for better coordination and cooperation between the institutions of health and social care. LTC-specific legislation is needed to define clear areas of responsibility for institutions and care providers to facilitate for example care transitions, thereby safeguarding consistency and continuity and improving quality of care [26]. It is hardly surprising, that LTC specific legislation (and implementation) are seen as an important factor for the future LTC [22].

As LTC has evolved from the private to the public sphere in the $20^{\text {th }}$ century, governments now obtain a more central role in guiding and organizing LTC. While foundation for care arrangements has previously strongly been within the family and community relationships, over time, government increasingly needed to assume this foundation-building role by means of legislation, regulation and contracting $[1,27]$. This can also explain why LTC legislation and implementation have developed slowly over time.

\section{Scale and scope in formal service provision}

The second main concern relates to the scale and scope of formal service provision, which fall under the dimension of LTC service delivery.

A limited scope of formal services for elderly persons is a challenge, because it can lead to unmet care needs. This challenge is partly due to the division between health and social care services. In particular, the scope of care services may be limited for institutional reasons. Initiatives to expand the scope of care services have previously succeeded by reaching better integration between health and social care provision [28]. Besides, the scope of service delivery may be increased through financial investment in new forms of care, e.g. innovative housing concepts, which is related to the LTC financing dimension $[29,30]$. Specific political decisions made in LTC financing can therefore impact the range of LTC service delivery.

More formal service provision, also for home care and outpatient care has been demanded in the past and increasing scale and scope is still expected for the future which is in line with general trends of increasing demand for user-centered service delivery [1]. To increase access to care (quantity), eligibility criteria will need to be revised and extended implying revision of legislation and regulation [22]. Also, the increase in the scale and scope of formal service provision depends on professionals in service delivery, meaning that adequate workforce capacities must be in place [31]. Despite ongoing discussion on changes in funding, the funding of care needs and budgeting for future needs are assessed as main challenges. This is expected given the tight public budgets and austerity measures $[4,3,32,33]$.

Thus, financial planning considerably impacts the availability of and accessibility to care services. This does not only refer to the size of the public budgets available to be spent on LTC, but also to the payment mecha- 
nisms which create (des)incentives for improving quality of care for formal care workers in domestic labor markets $[22,34]$. However, adopted legislations and regulations are decisive for care funding and subsequent service delivery. One way of mitigating the lack of public financial resources for LTC would be the support of public-private partnerships which represents a change in governance [35]. Through such partnerships, governments could contract private care providers, which is often related to private investment hence partly shifting financing obligation from the government to private firms [36, 37].

\section{Workforce planning and capacity building}

The third main concern is connected to workforce planning and workforce capacity building which fall under the dimension of LTC workforce.

While ongoing national discussions on building the care work capacity are addressed by country experts, workforce emigration is expressed as a pressing challenge. This finding may be explained by the selection of countries for this study and the relative importance of workforce emigration for the national LTC policy. As pointed out in the preceding paragraph, recruitment and retention of workforce is also dependent on the creation of related (financial) incentives, on labor market mechanisms, but as well on public investment in professional education $[22,38]$.

The need to raise attractiveness and financial incentives for the employment in formal care professions, has been recognized in the past and is still relevant for the future, as care workers currently face critical work conditions and financial disincentives [39, 40]. What is more, recruitment policies in the countries receiving workers from other countries, are confronted with normative perspectives on goals and objectives of LTC. Existing research on the critical (social) impact of care work emigration on home countries, poses questions to the morality of recruiting care workforce from economically weaker countries $[13,41]$. Policy solutions for workforce planning and capacity building are therefore depending on both, considerations of LTC guiding principles and LTC financing.

\section{E-health and information technologies}

The fourth main concern has to do with e-health and information technologies, which fall under the dimension of LTC information systems and technology.

While e-health development is addressed by the country experts, related national infrastructures and organizational characteristics are a challenge. Infrastructures hereby relate to the resources available to establish functional e-health systems, including technology and knowhow. Here, the influence of the LTC financing dimension becomes apparent, as private service providers, but as well public institutions, depend on funding (or subsidy) of technology and on investments in professional education $[22,42]$. In countries where funding of information technology is insufficient, chances for increased inter- communication and coherence in care service delivery are missed [26, 43]. Ongoing trends towards further development of and investment in information technology for LTC have previously been described, with the promise of maintaining and improving care recipient's quality of life and saving national household budgets [33]. Still, such ambitions are constrained by financial means, as described above.

In addition, organizational characteristics relate to structures that create a barrier to development, such as reluctance of professionals to adapt to new technology and need for legislation to regulate concerns of data protection, both of which touch upon the dimensions of LTC guiding principles and LTC governance. Such barriers are expected as the use of new technology is confronted with normative considerations in relation to goals and objectives of LTC, for example in the introduction of robotic technology to support care for elderly persons and its implications for them, their direct surroundings but also society [44].

Increased data collection and exchange have been pushed forward in the past and are expected for the field of e-health in the future, but will rely on adequate and clear legal boundaries for privacy aspects, which boundaries need to be set by the government [43, 45]. The realization of e-LTC as a comprehensive network between electronic social and health care records, is only a projection for the future but would strongly depend on decision making in LTC governance. Still, it is a relevant component for improved LTC in the future [1]. The promotion of e-technology among care users and improving its user-friendliness is another precondition for the digital transition in LTC.

\section{Study strengths and limitations}

This study provides a comprehensive approach to the analysis of the LTC systemic features, as well as national LTC structures in ten European countries. In addition, the combination of the analysis of policy report and data from qualitative study among country experts allowed for a triangulation of the findings. However, the sample size was limited (one participant per country), which prevents the triangulation of opinions per country. To receive data representative for Europe as a region, geographic variety of countries was considered. Nevertheless, the study cannot be representative for Europe because the Scandinavian region was not included. To ensure the clarity of answers and avoid misunderstandings or misinterpretations, online questionnaire was combined with follow up interview with the country experts. Even though the study was supported by the entire research team, the primary data analysis was conducted by the main researcher and a certain degree of subjectivism cannot be excluded.

\section{Conclusion}

In the presence of societal change and limited public budgets, the organization and provision of LTC for citizens poses a considerable challenge to European coun- 
tries. Policy makers are thereby confronted with the complexity of LTC systems, as presented at the outset of this paper.

This study has identified main concerns across the LTC sectors of ten European countries, namely Albania, Bulgaria, France, Germany, Lithuania, The Netherlands, Poland, Portugal, Ukraine and The United Kingdom. Although the study did not involve all European countries, findings on the relationship between LTC policy issues are universal and can therefore be a starting point for LTC system analysis in other countries as well.

To account for the interconnectedness of LTC issues, policy makers should adopt holistic approaches by considering the complexity of LTC when developing single policies within the seven dimensions of the LTC framework presented in this paper. Based on the similarity between the health systems and LTC systems, policy makers are encouraged to seek orientation and inspiration for future LTC policy from established health-related policy [1]. Stronger consideration of LTC in domestic policies is recommended. For this purpose, key stakeholders and interest groups ought to be considered, to foster dialogue and knowledge exchange as a basis for the establishment of a leading decision-making body [46].

Furthermore, financial and managerial support may be sought from EU funding and EU expert groups. Ambitions towards more integrated care policy are visible in many European countries. However, further research is needed to explore concrete strategies of implementing and further assessing the feasibility depending on national institutional structures.

\section{References}

1. Leichsenring K., Billings J., Nies H., Long-term care in Europe: Improving policy and practice, Palgrave Macmillan, Basingstoke, UK 2013.

2. Huber M., Rodrigues R., Hoffmann F., Gasior K., Marin B., Facts and Figures on Long-term Care. Europe and North America, European Centre, Vienna 2009, https://www.berndmarin.eu/wp-content/uploads/2017/09/2009-Facts-and-Figures-on-Long_Term-Care_Europe-and-North-America_over view.pdf (accessed: 10.08.2019).

3. Deusdad B.A., Pace C., Anttonen A., Facing the challenges in the development of long-term care for older people in Europe in the context of an economic crisis, "Journal of Social Service Research" 2016; 42 (2): 144-150, https:// www.tandfonline.com/doi/full/10.1080/01488376.2015.11 33147 (accessed: 10.08.2019).

4. Gori C., Changing long-term care provision at the local level in times of austerity - a qualitative study, "Ageing \& Society" 2018; 1-26, https://www.cambridge.org/core/journals/ageing-and-society/article/changing-longterm-care-pro vision-at-the-local-level-in-times-of-austerity-a-qualitativestudy/76B69E558F9ACDBE8067E216A768B20B (accessed: 10.08.2019).

5. Brodsky J., Habib J., Hirschfeld M., Key policy issues in long-term care, World Health Organization, Geneva 2003.

6. European Commission, Joint Report on Health Care and Long-Term Care Systems \& Fiscal Sustainability, Vol. 2,
European Commission, Brussels 2016, https:/publications. europa.eu/en/publication-detail/-/publication/8f7a1f6b-b53811e6-9e3c-01aa75ed71a1/language-en (accessed: 10.08.2019).

7. Kraus M., Riedel M., Mot E., Willemé P., Röhrling G., A Typology of Long-Term Care Systems in Europe, ENEPRI Research Report No. 91, August 2010, https://irihs.ihs. ac.at/id/eprint/3649/1/ENEPRI\%20RR\%20No\%2091\%20 Typology $\% 20$ of $\% 20$ LTC $\% 20 \% 20$ Systems $\% 20$ in $\% 20$ Europe.pdf (accessed: 10.08.2019).

8. Anderson J.E., Public policymaking: Cengage Learning, Stamford, CT 2014.

9. WHO, Everybody's business-strengthening health systems to improve health outcomes: WHO's framework for action, 2007, https://apps.who.int/iris/bitstream/handle/10665/ 43918/9789241596077_eng.pdf (accessed: 10.08.2019).

10. Kapllanaj M., Pino S., Haxhiymeri E., Mother employment and the role of care services in Albania, "European Scientific Journal" 2016; 12 (5): 129-139.

11. Vullnetari J., King R., 'Does your granny eat grass?' On mass migration, care drain and the fate of older people in rural Albania, "Global Networks" 2008; 8 (2): 139-171.

12. Vullnetari J., King R., 'Washing men's feet': Gender, care and migration in Albania during and after communism, "Gender, Place \& Culture" 2016; 23 (2): 198-215.

13. Hirose K., Czepulis-Rutkowska Z., Challenges in Longterm Care of the Elderly in Central and Eastern Europe, ILO DWT and Country Office for Central and Eastern Europe, Budapest 2016, https://www.ilo.org/budapest/what-wedo/publications/WCMS_532427/lang--en/index.htm (accessed: 10.08.2019).

14. Lipsitz L.A., The Elderly People of Post-Soviet Ukraine: Medical, Social, and Economic Challenges, "Journal of the American Geriatrics Society” 2005; 53 (12): 2216-2220.

15. Tolstokorova A.V., Gender Implications of Care Migration for the Operation of Care Diamond in Ukraine, "Diversities" 2013; 15 (1): 37-50.

16. Small B.H., Siewert G.A., Porrazzo J., Evaluating LongTerm Health Care Options for the Elderly in Albania, 2015, https://digitalcommons.wpi.edu/iqp-all/3338/ (accessed: 10.08.2019).

17. Barker K.K., Bosco C., Oandasan I.F., Factors in implementing interprofessional education and collaborative practice initiatives: Findings from key informant interviews, "Journal of Interprofessional Care" 2005; 19 (supl.): $166-176$.

18. Christmas C., Kravet S.J., Durso S.C., Wright S.M., Clinical excellence in academia: Perspectives from masterful academic clinicians, Paper presented at the Mayo Clinic Proceedings, 2008, https://www.sciencedirect.com/science/ article/abs/pii/S0025619611606010 (accessed: 10.08.2019).

19. Kiffin-Petersen S., Murphy S.A., Soutar G., The problemsolving service worker: Appraisal mechanisms and positive affective experiences during customer interactions, "Human Relations" 2012; 65 (9): 1179-1206.

20. King N., Brooks J.M., Template analysis for business and management students, Sage, London 2016.

21. Pfau-Effinger B., Culture and welfare state policies: Reflections on a complex interrelation, "Journal of Social Policy" 2005; 34 (1): 3-20. 
22. European Commission, Joint Report on Health Care and Long-Term Care Systems \& Fiscal Sustainability, Vol. 1, European Commission, Brussels 2016, https://publications. europa.eu/en/publication-detail/-/publication/d6042a45-b53511e6-9e3c-01aa75ed71a1/language-en (accessed: 10.08.2019).

23. Coleman E.A., Falling through the cracks: Challenges and opportunities for improving transitional care for persons with continuous complex care needs, "Journal of the American Geriatrics Society" 2003; 51 (4): 549-555.

24. Lau J.Y.C., Wong E.L.Y., Chung R.Y., Law S.C., Threapleton D., Kiang N.,..., Yeoh E.K., Collaborate across silos: Perceived barriers to integration of care for the elderly from the perspectives of service providers, "The International Journal of Health Planning and Management" 2018; 33 (3): e768-e780.

25. Uittenbroek R.J., Kremer H.P., Spoorenberg S.L., Reijneveld S.A., Wynia K., Integrated care for older adults improves perceived quality of care: results of a randomized controlled trial of embrace, "Journal of General Internal Medicine" 2017; 32 (5): 516-523.

26. Marcotte L., Kirtane J., Lynn J., McKethan A., Integrating health information technology to achieve seamless care transitions, "Journal of Patient Safety" 2015; 11 (4): 185-190.

27. Da Roit B., Le Bihan B., Similar and yet so different: Cashfor-care in six European countries'long-term care policies, “The Milbank Quarterly" 2010; 88 (3): 286-309.

28. Challis D., Chesterman J., Luckett R., Stewart K., Care management in social and primary health care: The Gateshead Community Care Scheme, Routledge, Abingdon, UK 2018.

29. Arentshorst M.E., Kloet R.R., Peine A., Intergenerational Housing: The Case of Humanitas Netherlands, "Journal of Housing For the Elderly" 2019; 33 (3): 244-256.

30. Tinker A., Ginn J., Ribe E., Assisted living platform: The long term care revolution. A study of innovatory models to support older people with disabilities in the Netherlands, King's College London, London 2013, https://www.ifa-fiv. org/wp-content/uploads/2013/11/HLIN-Report-LTC-Revolution.pdf (accessed: 10.08.2019).

31. Chen L., Evans T., Anand S., Boufford J.I., Brown H., Chowdhury M.,..., Elzinga G., Human resources for health: Overcoming the crisis, "The Lancet" 2004; 364 (9449): 1984-1990.

32. Daly T., Armstrong P., Liminal and invisible long-term care labor: Precarity in the face of austerity, "Journal of Industrial Relations" 2016; 58 (4): 473-490.

33. Greve B., Long-term care for the elderly in Europe: Development and prospects, Routledge, Abingdon, UK 2016,.
34. Costa-Font J., Courbage C., Swartz K., Financing longterm care: ex ante, ex post or both? "Health Economics" 2015; 24: 45-57, https://onlinelibrary.wiley.com/doi/ abs/10.1002/hec.3152 (accessed: 10.08.2019).

35. Vabo S.I., Actors and governance arrangements in longterm care for older people, in: Y. Kazepov, Rescaling Social Policies towards Multilevel Governance in Europe, Routledge, Abingdon, UK 2017: 343-363.

36. Barlow J., Roehrich J., Wright S., Europe sees mixed results from public-private partnerships for building and managing health care facilities and services, "Health Affairs" 2013; 32 (1): 146-154.

37. Costa-Font J., Courbage C., Long-Term Care Insurance: Partnership or Crowding Out?, in: J. Costa-Font, C. Courbage, Financing Long-Term Care in Europe, Palgrave Macmillan, London 2012: 91-100.

38. Hussein S., Manthorpe J., An international review of the long-term care workforce: Policies and shortages, "Journal of Aging \& Social Policy” 2005; 17 (4): 75-94.

39. Aiken L.H., Sloane D.M., Bruyneel L., Van den Heede K., Sermeus W., Consortium, R. c., Nurses' reports of working conditions and hospital quality of care in 12 countries in Europe, "International Journal of Nursing Studies" 2013; 50 (2): $143-153$.

40. Hollinger-Smith L., Ortigara A., Changing culture: Creating a long-term impact for a quality long-term care workforce, “Alzheimer's Care Today" 2004; 5 (1): 60-70.

41. Jecker N.S., Chin J.J.L., Justice and global care chains: Lessons from Singapore, "Developing World Bioethics" 2018; 19 (3): 155-168.

42. Georgiou A., Marks A., Braithwaite J., Westbrook J.I., Gaps, disconnections, and discontinuities - the role of information exchange in the delivery of quality long-term care, "The Gerontologist" 2012; 53 (5): 770-779.

43. van der Haak C.S., Mileski M., Alaytsev V., Carol E., Williams A., Adoption factors associated with electronic health record among long-term care facilities: A systematic review, "BMJ Open" 2015; 5 (1): e006615.

44. Čaić M., Odekerken-Schröder G., Mahr D., Service robots: Value co-creation and co-destruction in elderly care networks, "Journal of Service Management" 2018; 29 (2): 178-205.

45. van der Haak M., Wolff A.C., Brandner R., Drings P., Wannenmacher M., Wetter T., Data security and protection in cross-institutional electronic patient records, "International Journal of Medical Informatics" 2003; 70 (2-3): 117-130.

46. Fernandez S., Rainey H.G., Managing successful organizational change in the public sector, in: R.F. Durant, J.R.S. Durant, Debating Public Administration, Routledge, Abingdon, UK 2017: 7-26. 